\title{
Regional characteristics of foreign- born people living in the United Kingdom
}

By Alice Reid and Caroline Miller, Office for National Statistics

\section{Abstract}

This article examines the characteristics of foreign-born people living in the UK: how they differ between regions and countries, and from people born in the UK. Demographic, social and economic characteristics are examined using data from the Annual Population Survey (APS), 2009 .

The article looks first at the characteristics of the foreign-born population at a national UK level and the regional differences between foreign-born populations. It then compares the foreignborn and UK-born populations at regional level for each region and country of the UK.

\section{Key findings}

The following is a summary of the key findings from the article:

- the foreign-born population has recently been settling in different regions and countries from where they historically settled

- the age structure of the foreign-born population varies across the UK, while the UK-born population age structure is relatively similar between areas

- for the majority of regions and countries the proportion of the foreign-born population who are married or in civil partnerships in 2009 is higher than that of the UK-born population

- White is the largest ethnic group among foreign-born people in all regions and countries, except for the West Midlands where the largest ethnic group is Asian

- the largest percentage of both the foreign- and UK-born populations in each region and country are Christian; the Muslim population is also of a notable size in some regions

- the types of occupation in which foreign-born people are employed varies by region and country, and typically differs from the occupations of those born in the UK

- a smaller percentage of foreign-born people claim state benefits/tax credits than UK-born in all regions and countries except London. The percentage of state benefit/tax credit claimants 
varies by region and country for both populations, though this is more evident in the foreignborn population

\section{Introduction}

The main aim of this article is to investigate how the demographic, social and economic characteristics of the foreign-born population of the UK differ from those of the UK-born population. Data from the APS ${ }^{1}$ (2009) have been used, and characteristics compared between the regions of England and the other countries of the UK.

The report comprises two sections. The first is a report on the characteristics of the foreign-born population at a national UK level and how this differs between regions. The second gives a profile of foreign-born and UK-born populations at regional level for each region and country.

\section{Box 1 Definitions and technical information}

People who are not born in the UK are defined as those who answered the 'year of arrival' question on the APS and who said their country of birth was outside the UK. Information is available for foreign-born people who did not answer the date of arrival question; however, the numbers are generally quite small and they are therefore not included in the analysis. Please note that this definition is not the same as nationality as some people born outside the UK consider themselves to have British nationality. In 2009, 4.6 per cent of the UK population were born outside of the UK and considered themselves to have British nationality.

Percentage figures and rates shown in tables are based on weighted results from the survey. As the APS collects information from a sample of the population the information drawn from participants must be converted into estimates for the entire UK population. A weight is given to each participant based on the number of people each participant represents in the wider population. The reader should be aware that confidence intervals exist around these estimates. The main limitation of estimates is that they are subject to uncertainty due to the survey sampling process. Confidence intervals are included to make the accuracy of the estimates clear. The upper and lower bounds of a 95 per cent confidence limit are shown in the figures where appropriate.

The coefficient of variation is a way to summarise the variation of results in relation to the mean. If the level of variation is too high the estimates are not considered reliable. It is clearly indicated where these breach the acceptable limit of statistical robustness (when the coefficients of variation were equal to or greater than 20).

\footnotetext{
${ }^{1}$ Please see Annex A for a more detailed description of the APS and the dataset used for this article.
} 


\section{National and regional picture}

This section examines the differences in the characteristics of foreign- and UK-born people across regions and countries. Table 1 shows the distribution of the foreign-born ${ }^{2}$ population across the regions and countries of the UK.

\section{Table 1 Foreign- and UK-born populations: by region and country, and the regional share of the total foreign-born population of the UK, 2009}

United Kingdom

Percentages

\begin{tabular}{|c|c|c|c|c|}
\hline & $\begin{array}{r}\text { Foreign-born } \\
\text { population }\end{array}$ & $\begin{array}{r}\text { UK-born } \\
\text { population }\end{array}$ & $\begin{array}{l}\text { Regional share of total UK } \\
\text { population foreign-born }\end{array}$ & $\begin{array}{l}\text { Regional share of total UK } \\
\text { population UK-born }\end{array}$ \\
\hline North East & 5 & 95 & 2 & 4 \\
\hline North West & 7 & 93 & 7 & 12 \\
\hline Yorkshire and The Humber & 8 & 92 & 6 & 9 \\
\hline East Midlands & 8 & 92 & 5 & 7 \\
\hline West Midlands & 11 & 90 & 8 & 9 \\
\hline East & 10 & 90 & 8 & 9 \\
\hline London & 34 & 66 & 38 & 9 \\
\hline South East & 11 & 89 & 13 & 14 \\
\hline South West & 6 & 94 & 5 & 9 \\
\hline Wales & 5 & 95 & 2 & 5 \\
\hline Scotland & 6 & 94 & 5 & 9 \\
\hline Northern Ireland & 6 & 94 & 1 & 3 \\
\hline
\end{tabular}

Source: Annual Population Survey

Table 1 shows that, within the UK, London has the highest percentage of foreign-born residents within its population. Just over a third (34 per cent) of the residents here were not born in the UK, and over a third (38 per cent) of the foreign-born population of the UK live in London; this represents a foreign-born population of approximately 2.6 million $^{3}$ for London. The South East and West Midlands are the only other regions to have foreign-born populations over 10 per cent ( 0.9 million and 0.6 million people respectively), while the regions that are geographically furthest from London have the smallest percentage of their populations born outside the UK.

${ }^{2}$ Individuals recorded as born in Ireland 'area not specified' in the APS are treated as part of the foreign-born population.

${ }^{3}$ Population estimates in this article have been rounded. 


\section{Arrival year}

Figure 2 shows the arrival dates of the foreign-born population by region and country.

\section{Figure 2 Year of arrival for the foreign-born population, 2009}

United Kingdom

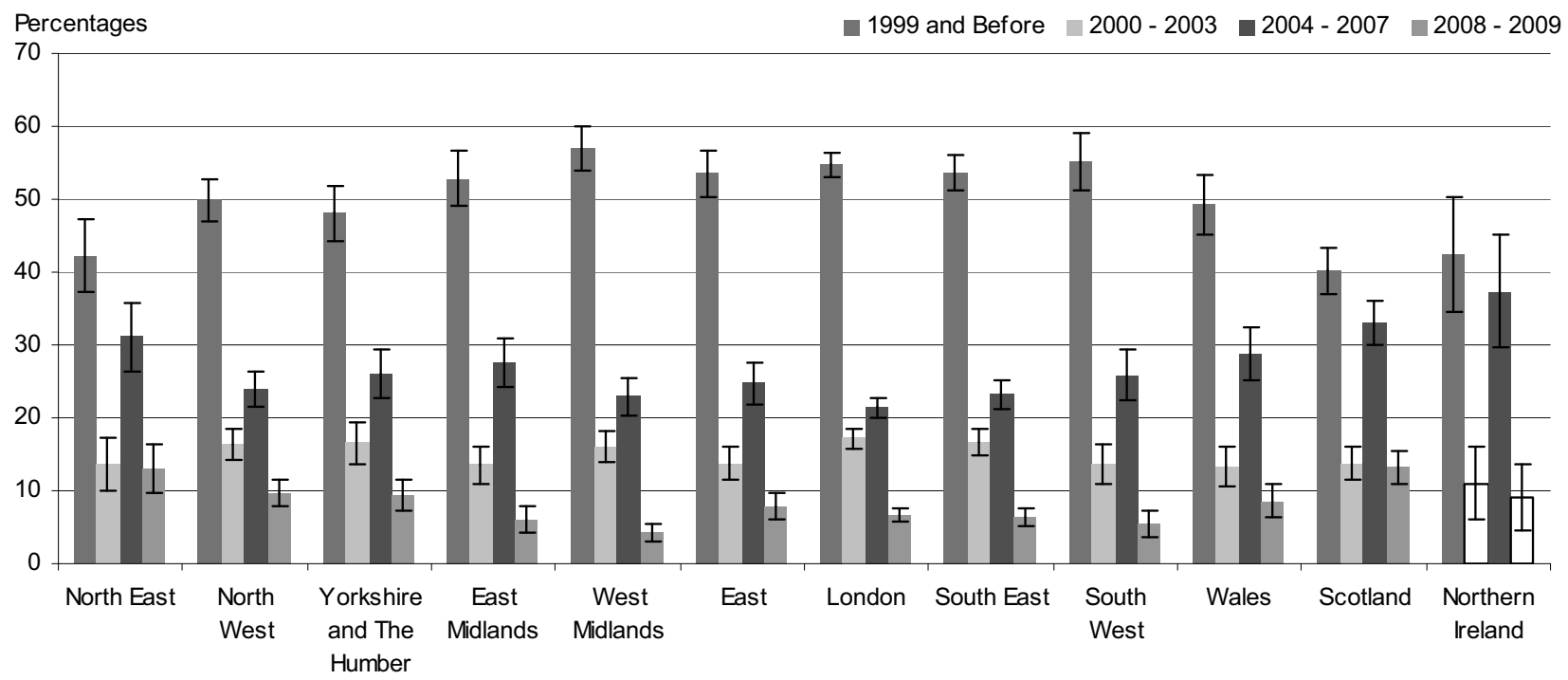

Please note that the Northern Ireland estimates for 2000 to 2003 and 2008 to 2009 have been whitened to indicate that they are unreliable.

Source: Annual Population Survey

Of the foreign-born population living in the UK, the majority arrived before 2000 , though for some parts of the UK the majority arrived later. Figure 2 shows that the proportions of foreign-born populations arriving before 2000 are typically largest in the midlands and southern regions of England. The proportions arriving after 2003 are largest in the North East, Scotland, Northern Ireland and, to a lesser extent, Wales. This indicates that foreign-born people are beginning to settle in different regions from where they historically settled. In particular, the proportions of the foreign-born population who arrived before 2000 are smaller in the North East and Scotland than in other areas. Conversely, the proportion of the foreign-born population who arrived in 2008 and 2009 is higher in these areas than in other areas. In the West Midlands, where the majority of its foreign-born population had arrived before 2000, only 4 per cent arrived in 2008 and 2009 compared with 13 per cent in both Scotland and the North East. 


\section{Age breakdown}

Figure 3 below shows the age breakdown of the foreign-born population by region and country. The age breakdown of the UK-born population is also provided as a comparator.

\section{Figure 3 Age distribution of the foreign- and UK-born populations, 2009}

United Kingdom
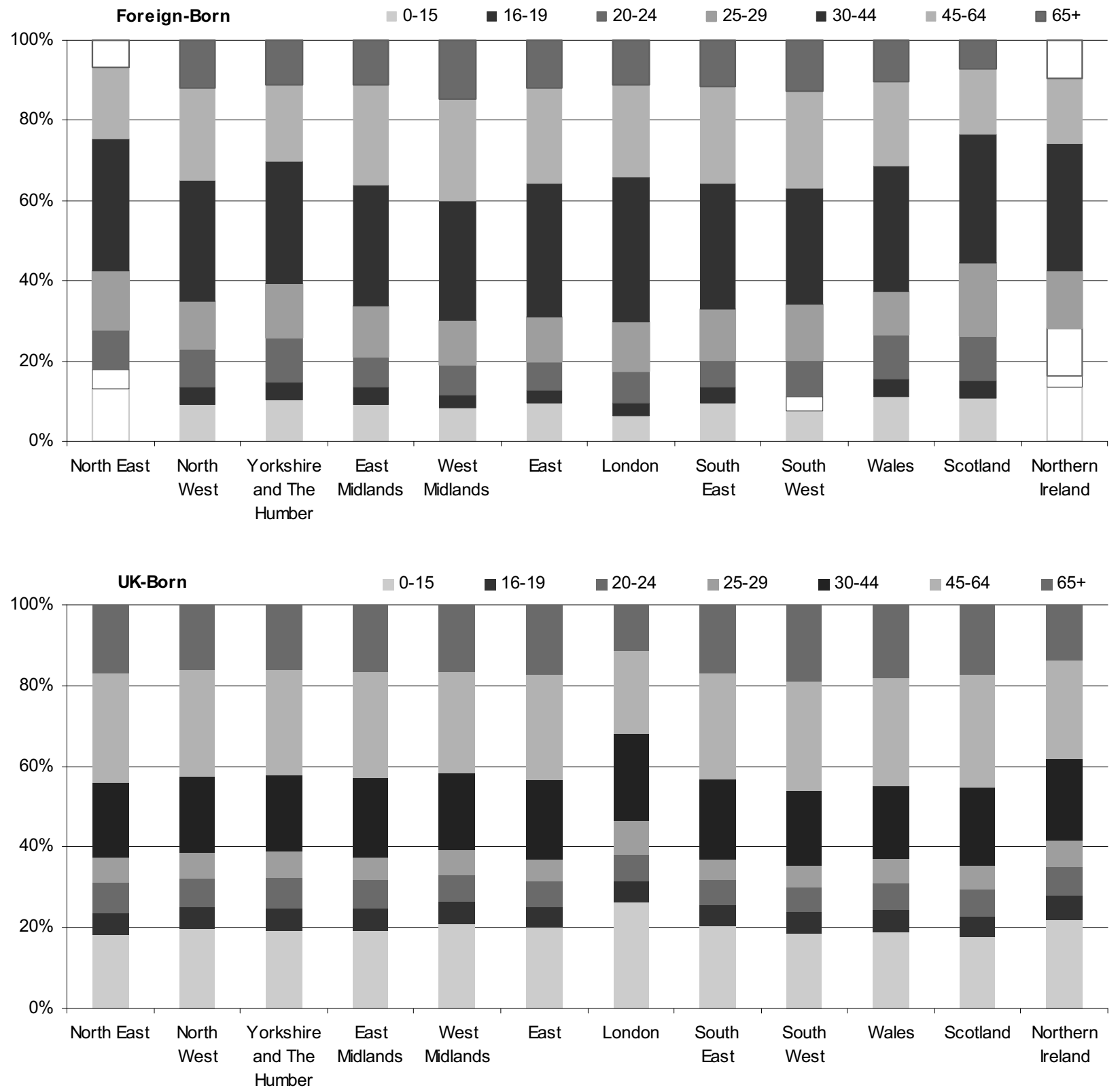

Please note that some age estimates are unreliable and have been whitened out.

Source: Annual Population Survey

Figure 3 shows that the age structure of the foreign-born population varies across the UK regions and countries in 2009 , while the age structure of the UK-born population is relatively similar for 
most areas. The 30 to 44 -year-old age group makes up the largest percentage of foreign-born people in each region, with the highest percentage found in London (36 per cent). The 45 to $64-$ year-old age group makes up the largest proportion among the UK-born in each region, with the exception of London where the 30 to 44 -year-old age group has a slightly higher percentage ${ }^{4,5}$.

The North East and Scotland both have larger proportions of the foreign-born population in the 25 to 29 and 30 to 44-year-old age groups than the other regions and countries. This reflects a larger proportion of the more recently settled foreign-born people in these regions. As the most recent arrivals are typically in these age groups, it follows that more established foreign-born populations are in the older age groups.

\section{Gender}

The percentages of males and females in the foreign-born population are similar across regions and countries. This follows the trend also seen in the UK-born population across the UK.

\section{Marital status}

There is a noticeable difference between the marital status of foreign- and UK-born populations. In 2009 a larger percentage of foreign-born people are married or in a civil partnership than for the UK-born population. This is illustrated in figure 4.

\footnotetext{
${ }^{4}$ Age bands have been used to maintain tight confidence intervals. Note that the age question on the APS applies to all people in the survey, and relates to their age during the reference week for the survey. Children who were born in the UK to foreign-born parents are, by definition, excluded from the foreign-born population.

${ }^{5}$ The arrival date of the foreign-born has not been analysed with age here, but may play a factor in age structure as the foreign-born who have been in the UK longer are likely to have an older age structure.
} 


\section{Figure 4 Single ${ }^{6}$ and married or civil partnered people in the foreign- and UK-born populations, 2009}

United Kingdom
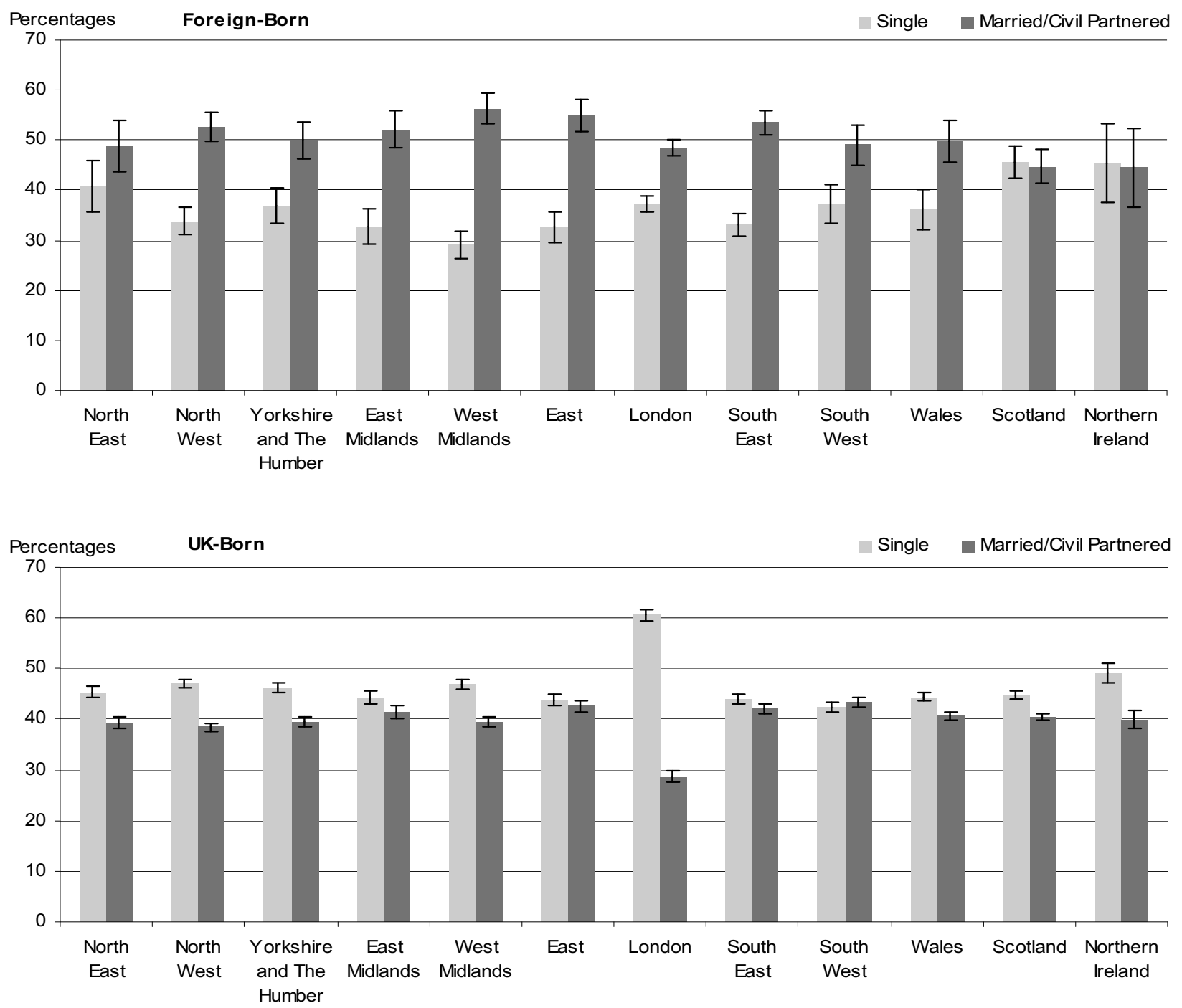

Source: Annual Population Survey

Figure 4 shows sizeable differences in the percentages of married/civil partnered and single people for those born in the UK compared with the foreign-born population ${ }^{7}$. With the exception of London, the UK-born population has relatively similar percentages of married or civil partnered people and single people in each region, whereas much greater variation between regions is evident in the foreign-born population.

In most parts of the UK, more foreign-born people are married/civil partnered than single, with the only exceptions being Scotland and Northern Ireland. Over all the regions, the West Midlands has one of the largest percentages of married or civil partnered foreign-born people (56 per cent)

\footnotetext{
${ }_{7}^{6}$ Single in this instance refers to people that have never married, regardless of age.

${ }^{7}$ Marital status is asked of all APS respondents, regardless of age. For this reason it is possible that the proportion of single UK-born people has been influenced by the UK-born children of parents born outside the UK.
} 
relative to single foreign-born people (29 per cent). In the UK-born population, more people are single than in marriages or civil partnerships for all regions except the South West. In the South West, 42 per cent of the population are single, while 43 per cent are married or in a civil partnership.

Notably, the foreign-born populations in the North East and Scotland both have higher proportions of single people than in most other regions and countries. This could be another reflection of the flow of recent foreign-born arrivals to these areas and their subsequent younger average age. With many marriages/civil partnerships occurring later in life, it follows that a younger population will have more single people than an older population.

\section{Ethnicity}

Table 5 is an illustration of the ethnic backgrounds of the foreign-born population across the UK.

\section{Table $5 \quad$ Ethnic background of the foreign-born population, 2009}

United Kingdom

\begin{tabular}{rrrrrrr} 
& & & & & & Percentages \\
\cline { 2 - 7 } & White & Mixed & Asian & Black & Chinese & Other \\
\hline North East & 44 & 1 & 30 & 6 & 6 & 12 \\
North West & 42 & $1^{*}$ & 33 & 8 & 3 & 13 \\
Yorkshire and The Humber & 44 & $1^{*}$ & 31 & 11 & 4 & 10 \\
East Midlands & 45 & $1^{*}$ & 31 & 12 & 4 & 7 \\
West Midlands & 32 & $1^{*}$ & 40 & 15 & 2 & 9 \\
East & 57 & $2^{*}$ & 21 & 8 & $3^{*}$ & 10 \\
London & 39 & $2^{*}$ & 27 & 18 & 2 & 12 \\
South East & 61 & $2^{*}$ & 20 & 7 & 2 & 7 \\
South West & 71 & $2^{*}$ & 11 & 7 & $2^{*}$ & 7 \\
Scotland & 59 & $2^{*}$ & 19 & 5 & $4^{*}$ & 13 \\
Northern Ireland & 67 & $2^{*}$ & 16 & 5 & 4 & 6 \\
\hline
\end{tabular}

* These figures are not considered statistically robust and are therefore unreliable

Source: Annual Population Survey

In all regions and countries with the exception of the West Midlands, the White foreign-born population is higher than for any other foreign-born ethnic group population. In the West Midlands, the largest foreign-born ethnic population in 2009 is Asian (40 per cent), compared with 32 per cent who are White. 


\section{Religion}

Table 6 shows the religious affiliations of the foreign-born population across regions and countries.

\section{Table 6 Religions of the foreign-born population, 2009}

Great Britain

\begin{tabular}{|c|c|c|c|c|c|c|c|c|}
\hline & \multicolumn{8}{|c|}{ Percentages } \\
\hline & Christian & Buddhist & Hindu & Jewish & Muslim & Sikh & $\begin{array}{r}\text { Other } \\
\text { Religion }\end{array}$ & $\begin{array}{r}\mathrm{No} \\
\text { Religion } \\
\end{array}$ \\
\hline North East & 54 & $2^{*}$ & 10 & $0^{*}$ & 18 & $3^{*}$ & $1^{*}$ & 13 \\
\hline North West & 47 & $1^{*}$ & 4 & $1^{*}$ & 34 & $1^{*}$ & 2 & 10 \\
\hline Yorkshire and The Humber & 48 & $1^{*}$ & 5 & $0^{*}$ & 31 & $1^{*}$ & 2 & 11 \\
\hline East Midlands & 54 & $1^{*}$ & 13 & $0^{*}$ & 16 & 4 & $2^{*}$ & 10 \\
\hline West Midlands & 44 & $1^{*}$ & 8 & $0^{*}$ & 29 & 9 & $2^{*}$ & 7 \\
\hline East & 63 & $2^{*}$ & 6 & $1^{*}$ & 13 & $2 *$ & $2^{*}$ & 12 \\
\hline London & 50 & 2 & 10 & 1 & 21 & 2 & 2 & 10 \\
\hline South East & 62 & 3 & 7 & $0^{*}$ & 11 & 2 & $2^{*}$ & 14 \\
\hline South West & 72 & $2^{*}$ & 3 & $0^{*}$ & 6 & $1^{*}$ & $2^{*}$ & 15 \\
\hline Wales & 60 & $3^{*}$ & 5 & $0^{*}$ & 15 & $0^{*}$ & 2 & 16 \\
\hline Scotland & 59 & $2^{*}$ & 5 & $1^{*}$ & 13 & $1^{*}$ & $1^{*}$ & 19 \\
\hline
\end{tabular}

* These figures are not considered statistically robust and are therefore unreliable

The religion question asked in Northern Ireland on the APS is different to that asked in the rest of the UK, therefore this country has not been included in this analysis.

Source: Annual Population Survey

The religion with the largest proportion of both the foreign- and UK-born populations in each region and country is Christian. Among the UK-born population, Muslims contribute a very small percentage across all regions, with the largest Muslim population being in London comprising 8 per cent of the UK-born population living there. The percentage of Muslims is much higher among the foreign-born population in all regions and countries, with particularly high percentages in the North West, comprising 34 per cent of all foreign-born living in this region, Yorkshire and The Humber (31 per cent) and the West Midlands (29 per cent). The South West has the lowest percentage (6 per cent). Sizeable percentages of the foreign-born population categorised as no religion are seen in each region and country, although the percentage of the UK-born population categorised as no religion is higher.

\section{Occupations}

The types of occupation in which foreign-born people are employed varies by region and country, and typically differs from the occupations of those born in the UK. Figures 7 and 8 illustrate the occupations of the foreign- and UK-born populations of the UK ${ }^{8}$.

${ }^{8}$ Occupations are based on the Standard Occupational Classification (SOC), 2000. The groupings used in this document are the nine major groups in the top tier of the classification. For more information see the Labour Force Survey User Guide Volume 5 (www.statistics.gov.uk/statbase/Product.asp?vlnk=1537). 


\section{Figure 7 Occupations of the foreign-born working population ${ }^{9}, 2009$}

United Kingdom
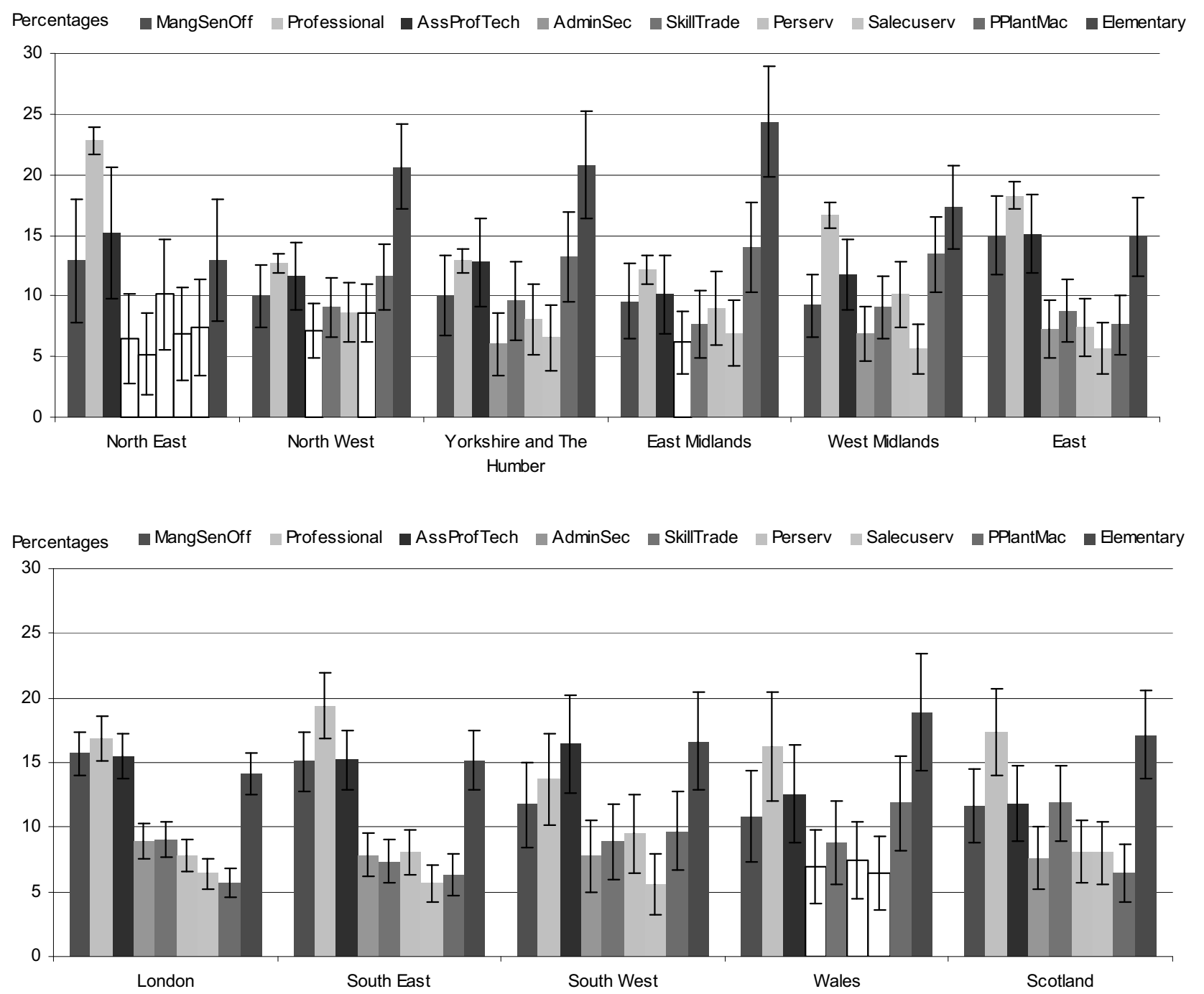

Please note that some occupation estimates are unreliable and have been whitened out. Northern Ireland has not been shown as all occupation estimates were unreliable.

Source: Annual Population Survey

This figure shows that there are differences in the distribution of the foreign- and UK-born populations across occupational categories in 2009. There are more foreign-born workers in elementary occupations than any other occupation in the East Midlands (24 per cent), the North West (21 per cent), Yorkshire and The Humber (21 per cent), and also sizeable percentages in Wales (19 per cent), the West Midlands (17 per cent) and Scotland (17 per cent). In contrast, there are substantial proportions of foreign-born workers in professional occupations in the North East (23 per cent) and South East (19 per cent).

\footnotetext{
${ }^{9}$ The major occupational groups for this analysis are: 1.Managers and Senior Officials, 2.Professional Occupations, 3.Associate Professional and Technical, 4.Administrative and Secretarial, 5.Skilled Trade Occupations, 6.Personal Service Occupations, 7.Sales and Customer Service Occupations, 8.Process, Plant and Machine Operatives, 9.Elementary Occupations.
} 
Over the rest of the UK, the highest percentages of foreign-born workers tend to be employed as a mixture of process, plant and machine operatives; associate professionals and technicians; and managers and senior officials. The smallest foreign-born percentages are seen in the sales, personal service and administrative occupations.

\section{Figure $8 \quad$ Occupations of the UK-born working population, 2009}

\section{United Kingdom}
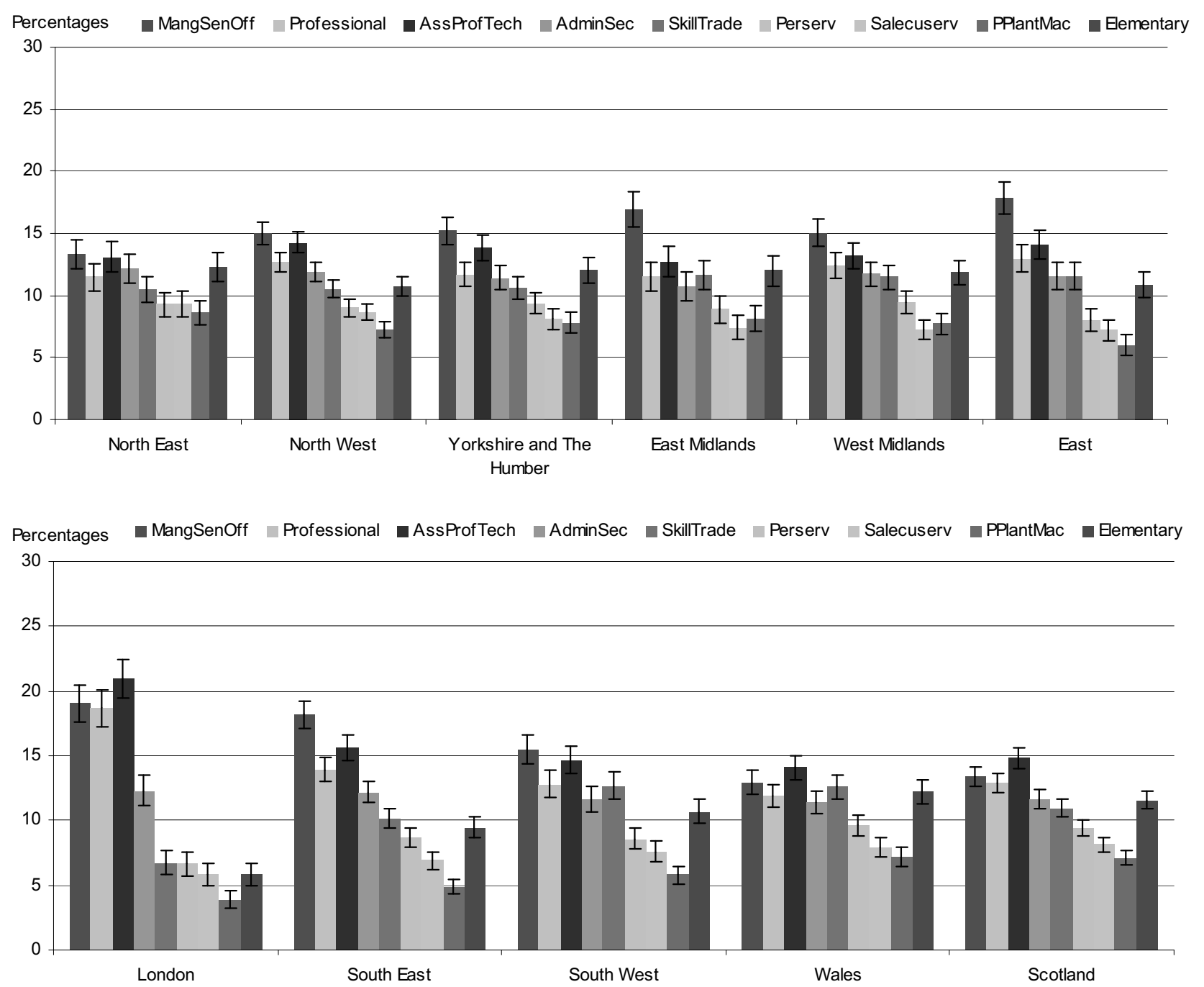

Source: Annual Population Survey

Among the UK-born population, the patterns in occupations across regions and countries show less variation. The highest percentages of UK-born people are in the senior management and associate, professional and technical occupations, while the lowest percentages are found in the sales and customer service and process, plant and machine operative occupations. 


\section{Earnings}

Despite the differences in occupations, there appears to be only a small difference between the earnings of the foreign- and UK-born populations. Figure 9 shows these differences, including a further breakdown between the foreign-born population from EU26 nations ${ }^{10}$ and those from the rest of the world ${ }^{11}$.

\section{Figure 9 Median net weekly earnings of the foreign- and UK-born populations, 2009}

United Kingdom

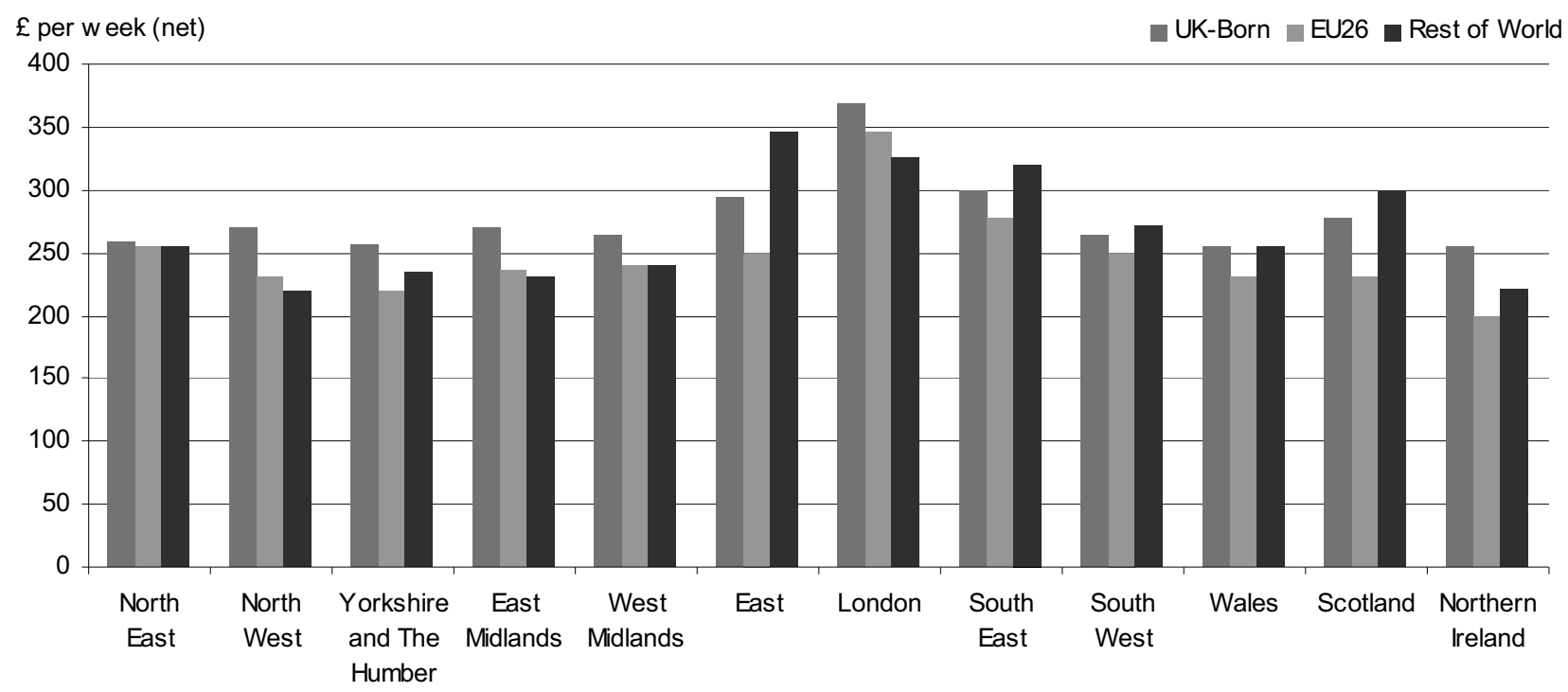

Source: Annual Population Survey

This figure shows that the earnings of the EU26 foreign-born and rest of the world foreign-born populations varies between regions and countries in 2009. It also shows that those born in the UK typically earn more than those from the EU26 nations. The largest regional variations are seen in the earnings of the foreign-born populations from the rest of the world. The foreign-born populations from the rest of the world earn more than the UK-born populations in three of the 13 regions and countries of the UK, less in seven and approximately the same in three.

\footnotetext{
${ }^{10}$ The EU26 nations are: Belgium, France, Luxembourg, Netherlands, Denmark, Sweden, Finland, Austria, Germany, Greece, Italy, Portugal, Spain (including Canary Islands), Ireland, Poland, Bulgaria, Romania, Estonia, Latvia, Lithuania, Hungary, Czech Republic, Slovakia, Slovenia, Cyprus and Malta.

${ }^{11}$ Rest of the world refers to: all countries of the world that are not in the group of 26 EU nations or the UK.
} 


\section{Qualifications}

Figure 10 shows the variation in qualifications by region and country ${ }^{12,13}$.

\section{Figure 10 Foreign- and UK-born populations with any type of qualification, 2009}

United Kingdom

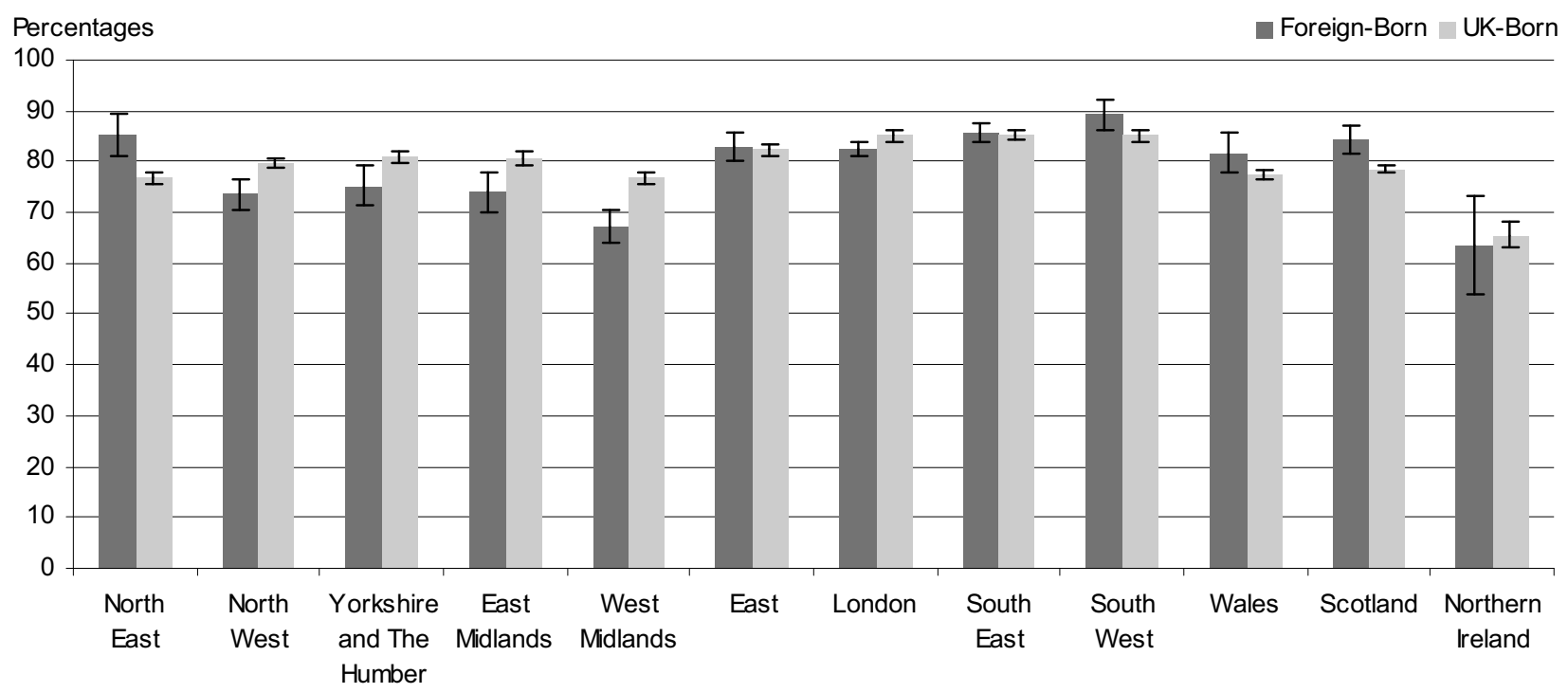

Source: Annual Population Survey

The percentage of the foreign-born population with qualifications varies by region and country in 2009. Northern Ireland (64 per cent) and the West Midlands (67 per cent) have the lowest percentages of the foreign-born population with qualifications. The percentages of foreign- and UKborn with a qualification also vary in each region and country. The largest difference is in the North East, where 85 per cent of the foreign-born population have a qualification compared with 77 per cent of the UK-born population. This is illustrated further when the percentage of foreign-born people with degrees is examined (figure 11).

\footnotetext{
${ }^{12}$ Qualification data is 'highest qualification held' and collected from all respondents aged 16-69 or those in employment (including respondents aged 70-99).

${ }^{13}$ Any type of qualification includes those with a degree, higher education qualification, other UK qualification or other qualification.
} 


\section{Figure 11 Foreign- and UK-born populations with a degree, 2009}

\section{United Kingdom}

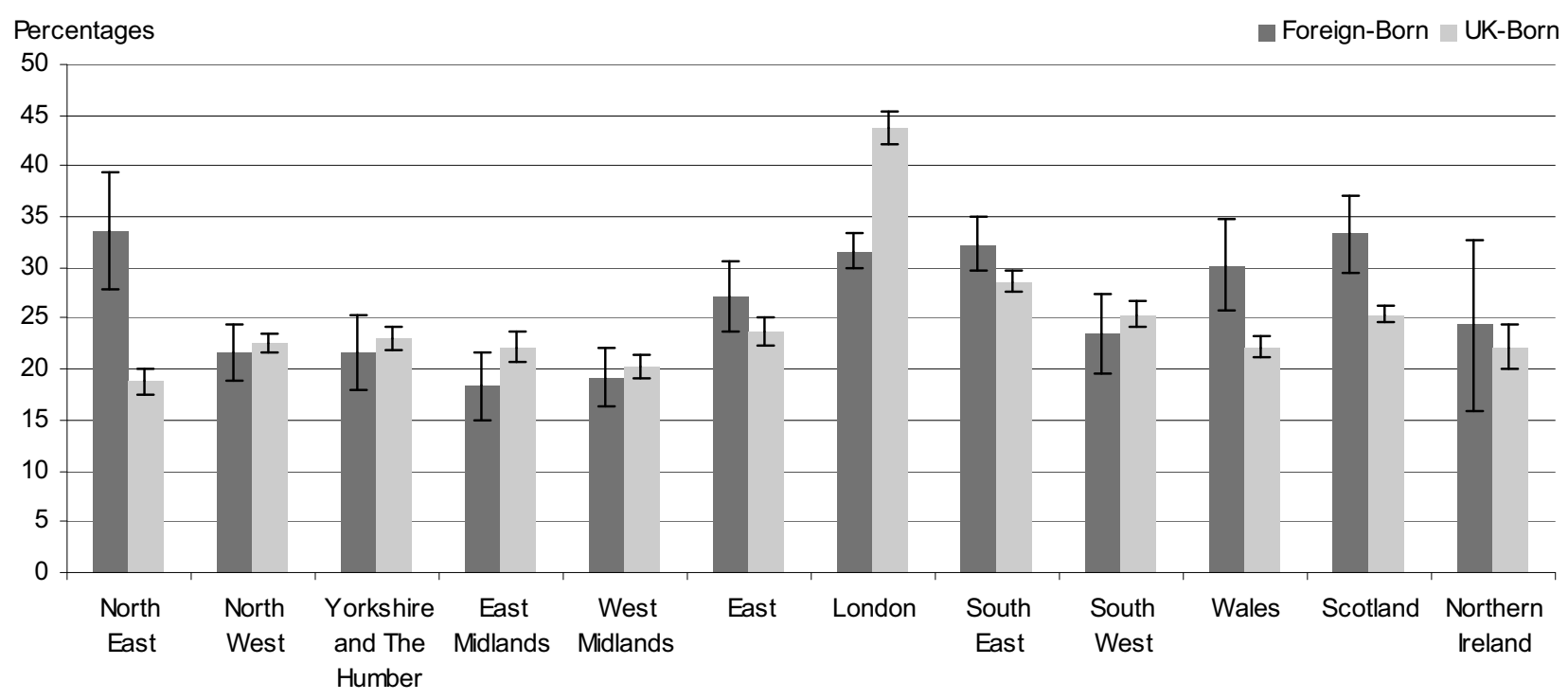

Source: Annual Population Survey

The percentage of both the UK-born and the foreign-born population with degrees differs by region and country in 2009. For example, in the North East, 34 per cent of the foreign-born population hold degrees, while in the East Midlands 18 per cent hold a degree. Differences also exist within regions in the number of people holding degrees for both foreign-born and UK-born populations. In London, 32 per cent of the foreign-born population hold a degree, while 44 per cent of the UK-born population have a degree. Conversely, the North West has similar percentages of both foreignand UK-born people with degrees (22 per cent and 23 per cent respectively). 


\section{Health}

Figure 12 is an illustration of the percentage of the foreign- and UK-born populations with current health problems ${ }^{14}$.

\section{Figure 12 Foreign- and UK-born populations with current health problems, 2009}

United Kingdom

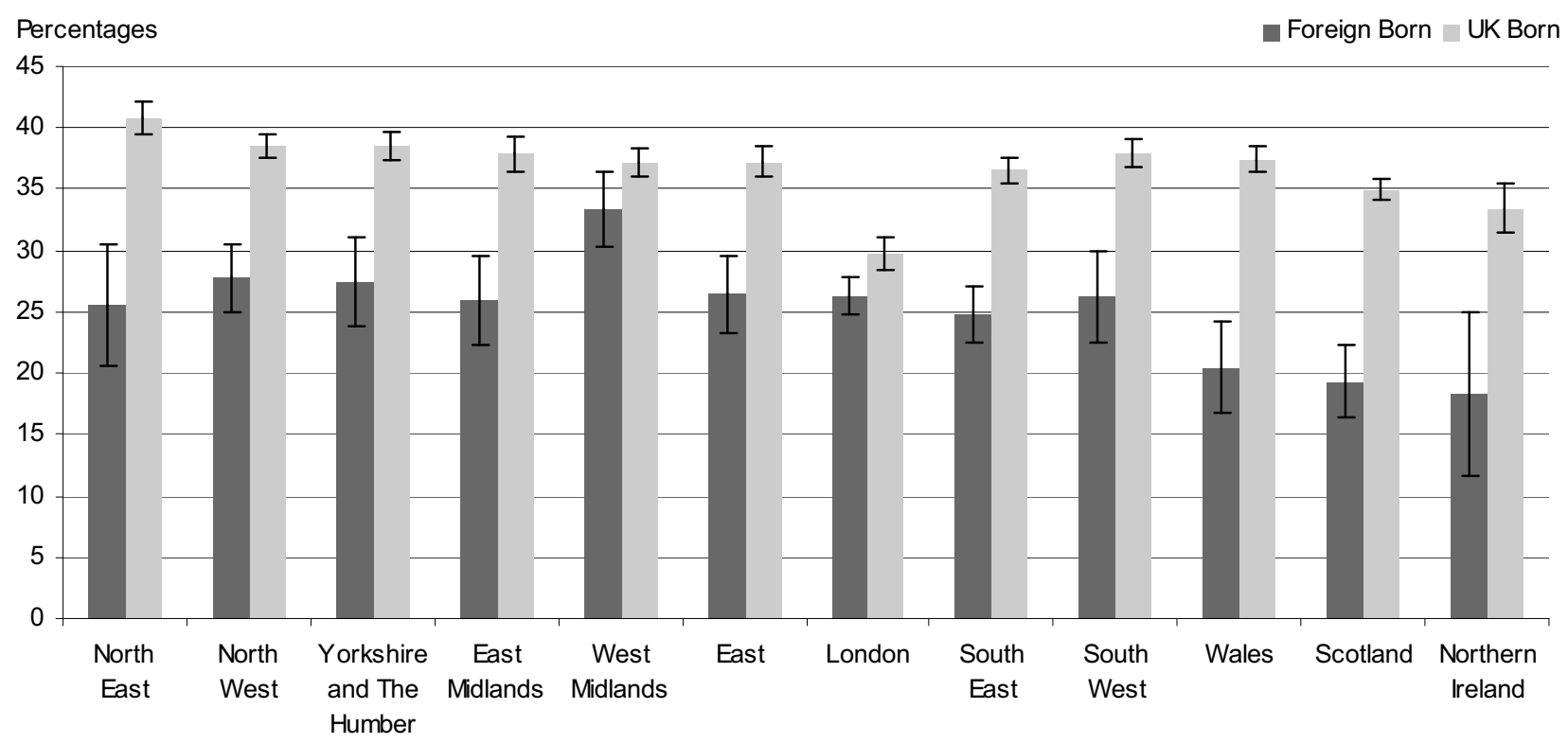

Source: Annual Population Survey

The percentage of the foreign-born population with health problems varies across the regions and countries of the UK in 2009 and is consistently lower than for the UK-born population. The highest percentage is found in the West Midlands (33 per cent). In Wales the difference between the foreign- and UK-born populations with current health problems is notably large. Here 21 per cent of the foreign-born and 37 per cent of the UK-born populations have current health problems.

\footnotetext{
${ }^{14}$ A current health problem is defined as a health problem lasting one year or more.
} 


\section{State benefits/tax credits}

Figure 13 illustrates the percentage of foreign- and UK-born people claiming state benefits/tax credits $^{15}$ in the UK.

\section{Figure 13 Foreign- and UK-born populations claiming state benefits/tax credits, 2009}

United Kingdom

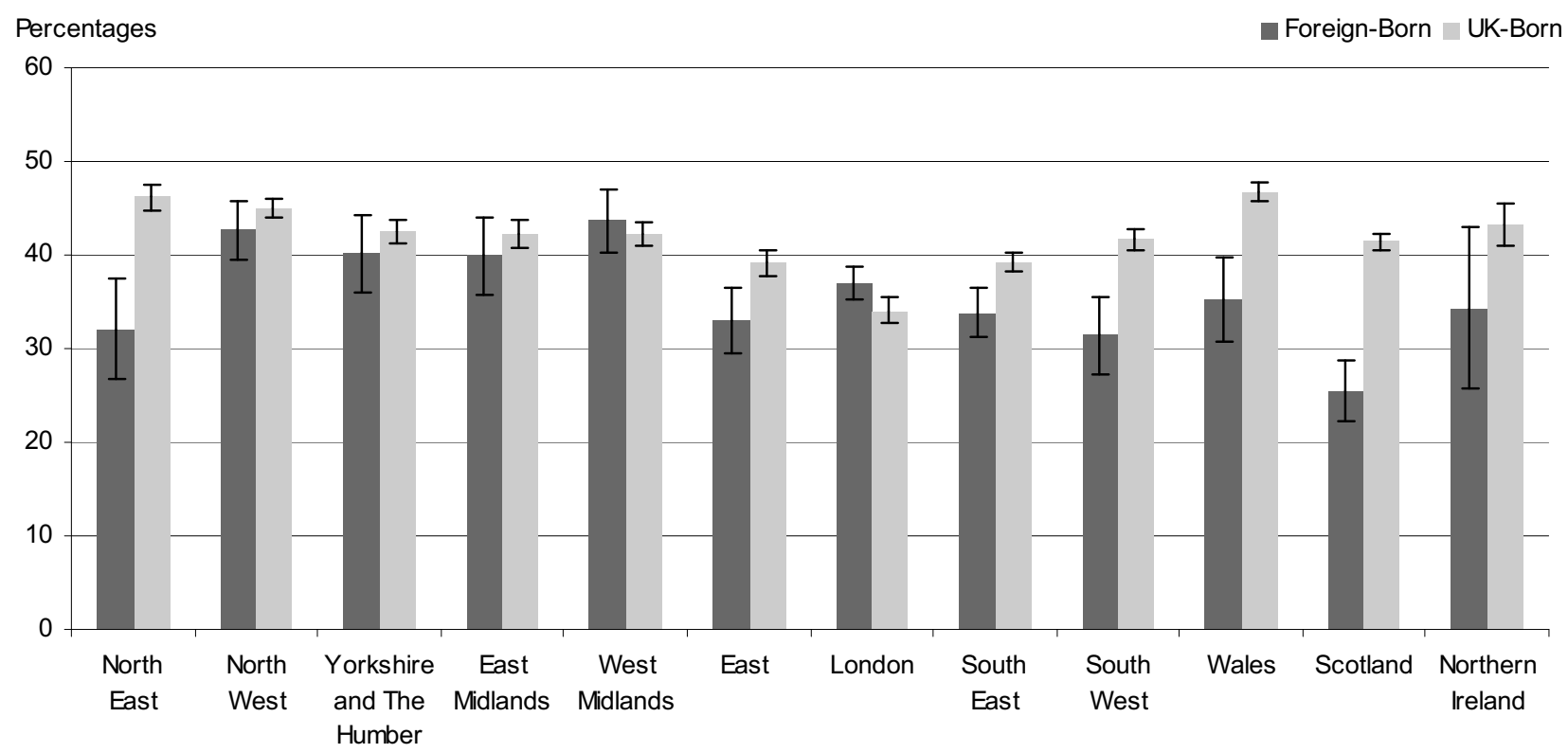

Source: Annual Population Survey

In 2009, fewer foreign-born people claim state benefits/tax credits than UK-born people in most regions and countries, with negligible differences in the West Midlands and London. The percentage of state benefit/tax credit claimants varies across the regions for both populations, though this is more evident in the foreign-born population. The smallest percentage of foreign-born people that claim state benefits/tax credits is in Scotland (26 per cent), while the largest is in the West Midlands (44 per cent) and the North West (43 per cent). Notably, there is a sizeable difference between the number of foreign-born and UK-born people in both the North East and Scotland that claim state benefits/tax credits.

\footnotetext{
${ }^{15}$ State benefits/tax credits refer to any type of state benefit/tax credit.
} 


\section{Regional profiles}

This section explores the differences between foreign- and UK-born populations for each region and country.

\section{North East}

The foreign-born population makes up 5 per cent of the total population in the North East (approximately 120,000 people) in 2009 , one of the smallest percentages of all the regions and countries of the UK. The foreign-born population of the North East represent 2 per cent of the total foreign-born population of the UK.

The age distribution of the foreign-born population in the North East follows the general trend of the foreign-born population across the UK. In 2009, the largest proportion, 33 per cent, are aged 30 to 44 years, compared with only 19 per cent for the UK-born population. In contrast, a higher percentage of UK-born than foreign-born are aged 0 to 15 years (18 per cent and 13 per cent respectively).

The percentage of the foreign-born population in the North East married or in a civil partnership in 2009 is noticeably higher (49 per cent) than the percentage of married or civil partnered people in the UK-born population (39 per cent). Conversely, the proportion of single people in the UK-born population (45 per cent) is similar to the foreign-born population (41 per cent).

The majority of the foreign-born population in the North East in 2009 are of a White ethnic background (44 per cent). Asian foreign-born people also make up a notable percentage (30 per cent). This is very different from the ethnic make-up of the UK-born population in this region, where 99 per cent have a White ethnic background.

Over half of the foreign-born population in the North East are Christians (54 per cent). This compares with an even higher percentage among the UK-born population (81 per cent). There is a larger proportion of Muslim foreign-born people in the North East than Muslims among the UKborn; 18 per cent and 1 per cent respectively. Similar proportions of the foreign- and UK-born populations are of no religion (13 per cent and 18 per cent respectively).

For the employed population, many of the occupation confidence intervals for those born in the UK and those born elsewhere overlap. This means that conclusions about occupational differences between them cannot be drawn with any certainty. However, it can be concluded that, of the employed, the foreign-born are more likely than those born in the UK to be in professional occupations (23 per cent and 12 per cent respectively) in 2009. The proportion of the UK-born population in each occupation is similar, though there are marginally larger percentages in the management, professional, assistant professional admin and elementary occupations than the remaining occupations. The median net weekly wage of the foreign-born population in the North East is similar (£254) to the UK-born population (£258).

People in the foreign-born population of the North East in 2009 are more likely to hold a degree (34 per cent) than people in the UK-born population (19 per cent). The foreign-born population are generally more qualified (85 per cent) than the UK-born population (77 per cent), in that they are more likely to hold some type of qualification. 


\section{North West}

The foreign-born population makes up 7 per cent of the total population in the North West (approximately 500,000 people) in 2009 , representing 7 per cent of the total foreign-born population in the UK.

There are sizeable differences between the age distribution of the foreign-born and the UK-born populations in the North West. The largest percentage of the foreign-born population in the North West is in the 30 to 44-year-old age group (30 per cent). In contrast, the largest percentage of the UK-born population in the region is the 45 to 64 -year-old age group (26 per cent). There is also a notable difference between foreign- and UK-born population percentages in the 0 to 15-year-old age group. Only 9 per cent of the foreign-born population fall within this category, compared with 20 per cent of the UK-born population.

In the North West, a larger percentage of the foreign-born population are married or in a civil partnership (53 per cent) than are single (34 per cent) in 2009. This differs from the marital status of the UK-born population, who are more likely to be single (47 per cent) than married or in a civil partnership (39 per cent).

In 2009, the largest percentage of the foreign-born population in the North West are of White ethnic origin (42 per cent), followed by Asian ethnic origin (33 per cent). The ethnic background of the UK-born population in the North West is typically White (95 per cent), with a small percentage of the UK-born having an Asian ethnic background (3 per cent).

The most common religion found among the foreign-born population of the North West is Christianity (47 per cent). Muslims account for over a third (34 per cent) of foreign-born people in the North West. There are also notable no religion (10 per cent) and Hindu (4 per cent) foreignborn populations. The most common religion among the UK-born population in the North West is also Christianity (79 per cent). One in six of the UK-born population in the North West have no religion (16 per cent), while a small percentage are Muslim (3 per cent).

Of those in employment, people who are not born in the UK are most likely to be employed in elementary occupations (21 per cent). UK-born people are most likely to be in management and senior official occupations (15 per cent) and associate professional and technician occupations (14 per cent).

The net median wage of the foreign-born population in the North West is less than that for the UKborn population in the region. For foreign-born people, the median wage is $£ 230$ per week, compared with a median wage of $£ 269$ per week for those born in the UK. The earnings of the foreign-born population also differs by country of origin. Those from the EU26 nations have higher earnings, at $£ 231$ per week, than those from the rest of the world at approximately $£ 219$ per week.

Fewer foreign-born than UK-born people in the North West hold some type of qualification; 80 per cent of those born in the UK hold some type of qualification, compared with 74 per cent of the foreign-born population. The percentage of the foreign-born population with a degree is 22 per cent. This is similar to the percentage of the UK-born population with a degree (23 per cent). 


\section{Yorkshire and The Humber}

The foreign-born population makes up 8 per cent of the total population in Yorkshire and The Humber (approximately 400,000 people) and 6 per cent of the total foreign-born population of the UK in 2009.

The largest age group for the foreign-born population is the 30 to 44-year-old age group (31 per cent). This differs from the UK-born population where the largest percentage is in the 45 to 64 year-old age group (26 per cent). In contrast, the percentage of foreign-born in the 45 to 64 -yearold age group is 19 per cent.

The foreign-born population who are married or in a civil partnership (50 per cent) is larger than those who are single (37 per cent). This differs from the marital status of the UK-born population who are more likely to be single (46 per cent) than married or in a civil partnership (39 per cent).

For the foreign-born population in Yorkshire and The Humber, the largest ethnic group is White (44 per cent). Asian is the next largest ethnic group (31 per cent), Black ethnic background make up 11 per cent, while 'other' ethnic backgrounds make up a further 10 per cent. This is different from the ethnicity of the UK-born population within the region in 2009, with 95 per cent being White. The Asian UK-born population is the second largest ethnic group, though the percentage is relatively small (4 per cent).

Almost half the foreign-born population of Yorkshire and The Humber identify themselves as Christian (48 per cent); in comparison, nearly three-quarters of the UK-born population identify themselves as Christian (72 per cent). Muslims make up 31 per cent of the foreign-born population of Yorkshire and The Humber in 2009, while the comparative percentage of UK-born Muslims is small at 3 per cent. The number of people with no religion is relatively high in both populations; the percentage of foreign-born in this group is 11 per cent, while the percentage of UK-born people in this group is 23 per cent.

Of the employed foreign-born population, the most common occupation is the elementary category (21 per cent). This differs from the UK-born population where the most common occupations are managers and senior officials (15 per cent) and associate, professional and technical occupations (14 per cent).

In 2009, the foreign-born population in Yorkshire and The Humber have fewer qualifications than those born in the UK; 81 per cent of those born in the UK hold some type of qualification, compared with 75 per cent for the foreign-born population. Of those with qualifications, 22 per cent of people not born in the UK hold a degree, which is similar to the percentage of the UK-born population with a degree (23 per cent).

The net median earnings of the foreign-born population in Yorkshire and The Humber are lower than those of the UK-born population in the region ( $£ 225$ and $£ 256$ per week respectively). The earnings of the foreign-born population also differ by country of origin. Those from the EU26 nations have lower earnings at $£ 219$ per week than those from the rest of the world who earn approximately £235 per week. 


\section{East Midlands}

The foreign-born population make up 8 per cent of the total East Midlands population (approximately 370,000 people) in 2009 . This accounts for 5 per cent of the total foreign-born population of the UK.

The age distribution of the foreign- and UK-born populations differ considerably in the East Midlands. In 2009, the largest foreign-born population is the 30 to 44-year-old age group (30 per cent). For the UK-born population, the 45 to 64 -year-old age group (26 per cent) is the largest. A relatively small percentage of the foreign-born population are in the 0 to 15-year-old age group ( 9 per cent), compared with a larger percentage for the UK-born population (19 per cent).

In the East Midlands, over half the foreign-born population in 2009 are married or in a civil partnership (52 per cent). This compares with only 41 per cent of the UK-born population. Conversely, the percentage of UK-born singles (44 per cent) is greater than that for the foreignborn population (33 per cent).

Almost half the foreign-born population of the East Midlands are of a White ethnic background (45 per cent) in 2009, while approximately a third are of an Asian ethnic background (31 per cent). This differs from the UK-born population where 95 per cent of the population are of a White ethnic background. A small percentage are from an Asian ethnic background ( 3 per cent).

Over half the foreign-born population in the East Midlands are Christian (54 per cent). A diverse range of religions make up the other half of this population: Muslims, 16 per cent; Hindus, 13 per cent; and no religion, 10 per cent. These percentages are different from the UK-born population, although Christian (72 per cent) is also the largest percentage of the UK-born population in 2009. The only other notable percentage is the no religion category, which makes up 23 per cent.

Of the employed, the most common occupation for the foreign-born population is the elementary category, which accounts for 24 per cent of this population. This differs from the employed UK-born population of the region where the most common occupation is the management and senior official occupation (17 per cent).

The percentage of the foreign-born population with qualifications (74 per cent) is lower in 2009 than the percentage of the UK-born population with qualifications (81 per cent). Of these populations, 18 per cent of the foreign-born population hold a degree, compared with 22 per cent for the UK-born population.

The net median weekly earnings of the UK-born population (£269) in this region are more than those of the foreign-born population (£231). Of the foreign-born population, those from the EU26 nations typically earn slightly more (£237) than those from the rest of the world (£231).

\section{West Midlands}

The foreign-born population make up 11 per cent of the total population of the West Midlands (approximately 570,000 people) in 2009 . This is one of the largest percentages by region and 
country within the UK and accounts for 8 per cent of the total foreign-born population of the UK in 2009.

With regard to age, the largest percentage of the foreign-born population is in the 30 to 44 -year-old age group (29 per cent). This differs from the UK-born population where the largest percentage is the 45 to 64 -year-old age group (25 per cent). The foreign-born population in this age group is very similar (26 per cent). The biggest difference between the foreign- and UK-born populations in this region in 2009 is in the 0 to 15-year-old age group; only 8 per cent of the foreign-born population are in this group, compared with 21 per cent for the UK-born population.

In the West Midlands, the percentage of the foreign-born population who are married or in a civil partnership (56 per cent) in 2009 is higher than the percentage of foreign-born singles (29 per cent). This differs from the marital status of the UK-born population who are more likely to be single; 47 per cent of this population are single, while 40 per cent are married or in a civil partnership.

In the West Midlands, Asian is the largest ethnic group for the foreign-born population (40 per cent). The White foreign-born make up the second largest group (32 per cent), and a notable percentage of the foreign-born population are of a Black ethnic background (15 per cent). The ethnic make-up of the UK-born population in the West Midlands is substantially different from the foreign-born population, with 91 per cent of the population in the White ethnic background category. The UK-born Asian ethnic origin population in the region make up 6 per cent of the total UK-born population in 2009.

Christians are the most prevalent among both the foreign-born and UK-born populations (44 per cent and 74 per cent respectively). In the West Midlands, Muslims make up a notable percentage of the foreign-born population (29 per cent); though they only make up a small percentage of the UK-born population (4 per cent) in 2009. Sikhs and Hindus make up a higher proportion of the foreign-born population ( 9 per cent and 8 per cent respectively) than the UK-born population ( 2 per cent and 1 per cent respectively). The percentage of the UK-born population who are of no religion (18 per cent) is much higher than that for the foreign-born population (7 per cent).

Of the foreign-born population in employment, the most typical occupations are the elementary (17 per cent), professional (17 per cent) and process, plant and machine operative (13 per cent) occupations. This is different from the UK-born population where the management and senior official occupations are the most common (15 per cent).

Fewer foreign-born than UK-born people hold any qualification in the West Midlands (67 per cent compared with 77 per cent respectively). The percentage of the foreign-born population with a degree is 19 per cent, which is slightly lower than the UK-born population ( 20 per cent).

In 2009, the net median weekly earnings of the UK-born population (£265) in this region are more than those of the foreign-born population (£240). Of the foreign-born population, those from the EU26 and those from the rest of the world earn approximately the same (£240). 


\section{East of England}

The foreign-born population of the East of England make up 10 per cent of the total East of England population (approximately 550,000 people); this is 8 per cent of the total foreign population of the UK in 2009.

By age, the largest percentage of the foreign-born population in the East is the 30 to 44 -year-old age group (33 per cent), followed by those aged 45 to 64 years (24 per cent). In contrast, the 45 to 64-year-old age group represents the largest percentage of the UK-born population in the region (26 per cent). In 2009, there is also a large difference between the foreign-born and UK-born population percentages for the 0 to 15 -year-old age group. Only 9 per cent of the foreign-born population fall within this category, compared with 20 per cent of the UK-born population.

The percentage of the foreign-born population of the East of England who, in 2009, are married or in a civil partnership is substantially higher (55 per cent) than the UK-born population (43 per cent). Conversely, more of the UK-born population are single (44 per cent) than the foreign-born population (33 per cent).

In 2009 in the East of England, 57 per cent of the foreign-born population are of a White ethnic background, compared with 96 per cent of the UK-born population. People of an Asian ethnic background make up the second largest percentage of the foreign-born population (21 per cent), though this group only make up 2 per cent of the UK-born population.

The largest percentage of the foreign-born population is Christian (63 per cent), followed by Muslim (13 per cent) and those with no religion (12 per cent). The most common religion among the UKborn population is Christianity (74 per cent), followed by those with no religion (22 per cent). Only a small percentage are Muslim (1 per cent).

Of the employed foreign-born population, the largest percentages are in professional (18 per cent), assistant professional and technical (15 per cent) manager and senior official (15 per cent), and elementary occupations (15 per cent). For the UK-born population, the manager and senior official occupation group (18 per cent) is the most common.

The percentage of the foreign-born population with qualifications (83 per cent) is similar to the percentage of the UK-born population with qualifications (82 per cent). The percentage of the foreign-born population with degrees (27 per cent) is also similar to that for the UK-born population (24 per cent).

The foreign-born population earn similar median net weekly amounts (£290) to the UK-born population (£294). However, of the foreign-born population, those from EU26 nations earn a substantially lower amount (£249) than both the foreign- and UK-born average. Those from the rest of the world earn substantially more (£346).

\section{London}

The foreign-born population make up 34 per cent of the total population of London (approximately 2.6 million people) in 2009. This is the largest foreign-born number and percentage of all the UK regions and countries and makes up 38 per cent of the total foreign-born population of the UK. 
The age structure of the foreign-born population is similar to that of the UK-born population in most age groups. However, there are notable differences in the 0 to 15 and 30 to 44-year-old age groups. The most extreme difference between the two populations is in the 0 to 15 -year-old age group where the percentage of the foreign-born population is only 6 per cent, while the UK-born percentage is much higher at 26 per cent. In the 30 to 44-year-old age group, there is a substantially larger foreign-born population (36 per cent) than UK-born population (22 per cent).

The percentage of the foreign-born population who are married or in a civil partnership (49 per cent) is higher than the percentage who are single (37 per cent) in 2009 . This is considerably different from the UK-born population of London, where only 29 per cent of people are married or in a civil partnership, and 61 per cent are single in 2009.

The percentage of the foreign-born population of a White ethnic background is 39 per cent in 2009; this is very different from the UK-born population where 76 per cent are of this ethnicity. The second largest ethnic group for the foreign-born population is Asian (27 per cent), followed by Black (18 per cent). By comparison, the percentage of the UK-born population in London of an Asian or Black ethnic group (both at 9 per cent) is much smaller than for the foreign-born population.

In London, half of the foreign-born population are Christians (50 per cent), compared with 63 per cent of the UK-born population. The foreign-born Muslim population is much larger than the UKborn population in London in percentage terms $(21$ per cent compared with 7 per cent respectively). In 2009 , the percentage of the foreign-born population with no religion (10 per cent) is noticeably smaller than for the UK-born population (22 per cent). There is also a notable percentage of Hindus in the foreign-born population (10 per cent), compared with 2 per cent in the UK-born population.

Of the foreign-born population in employment, most are in professional (17 per cent), management and senior official (16 per cent), associate professional and technical (16 per cent) and elementary (14 per cent) occupations. The UK-born population are most likely to be in the associate professional and technical (21 per cent), management and senior official (19 per cent) and associate professional and technical (19 per cent) occupations. In 2009, there is also a substantial difference between the proportions of the population in the elementary occupations, where the percentage of the foreign-born population is much higher than that for the UK-born population (14 per cent compared with 6 per cent respectively).

With regard to net median weekly earnings, the foreign-born population typically earn less (£336) than the UK-born population (£369). When the foreign-born population is further broken down by country of origin, those from EU26 nations earn more (£346) than those from the rest of the world (£326).

The percentage of the foreign-born population with qualifications ( 83 per cent) is similar to the percentage of the UK-born population with qualifications (85 per cent) in 2009. However, the percentage of the foreign-born population with degrees (32 per cent) is smaller than that of the UKborn population (44 per cent). 


\section{South East}

The foreign-born population of the South East make up 11 per cent of the total population for this region (approximately 900,000 people), representing 13 per cent of the total foreign-born population of the UK in 2009.

The largest percentage of the foreign-born population is in the 30 to 44-year-old age group (32 per cent); this compares with 20 per cent of the UK-born population. There is also a large difference between the populations in the 0 to 15-year-old age group; 10 per cent of the total foreign-born population are in this age group, less than half of the 20 per cent who were born in the UK.

In 2009 in the South East, a higher percentage of the foreign-born population are married or in a civil partnership (54 per cent) than are single (33 per cent). This differs from the UK-born population where more people are single (44 per cent) than are married or in a civil partnership (42 per cent).

By ethnic group, the largest percentage of the South East foreign-born population in 2009 are of White ethnic origin (60 per cent), followed by those of an Asian ethnic origin (20 per cent). The ethnic origins of the UK-born population differ from this, with a large percentage from a White ethnic background (97 per cent). Those of an Asian ethnic origin make up only 2 per cent of the total UK-born population of the region.

The most common religion found among the foreign-born population of the South East is Christianity (62 per cent). Also prevalent within the foreign-born population are people with no religion (14 per cent) and Muslims (11 per cent). The most common religion among the UK-born population is Christianity (76 per cent). The only other notable percentage in 2009 is that of the no religion group (21 per cent).

In the South East more of the foreign-born population are employed in the elementary and professional occupations (15 per cent and 19 per cent respectively) than the UK-born population (10 per cent and 14 per cent respectively).

The median net weekly earnings of the foreign-born population are the same as those for the UKborn population at $£ 300$ per week. However, the foreign-born population from the rest of the world typically earn more (£320) than both those from EU26 nations (£277) and the UK-born population.

The percentage of the foreign-born population in the South East with qualifications is similar to the UK-born population (86 and 85 per cent respectively) in 2009. Of the foreign-born population, 32 per cent of people hold a degree, which is more than the UK-born population where 29 per cent hold a degree.

\section{South West}

The foreign-born population make up 6 per cent of the total population in the South West (approximately 320,000 people) and 5 per cent of the total foreign-born population of the UK in 2009.

The age distribution of the foreign-born population in the South West follows the general trend seen for this population across the UK. The highest percentage of the foreign-born population is in 
the 30 to 44-year-old age group (29 per cent) in 2009, this compares with only 19 per cent for the UK-born population. The most notable difference between the foreign-born and UK-born populations is in the 0 to 15 -year-old age group. Here the percentage of the foreign-born population is much smaller (7 per cent) than the UK-born population (19 per cent). Conversely, for the 25 to 29 -year-old age group, the percentage of the foreign-born population is far larger (14 per cent) than the UK-born population (5 per cent).

The percentage of those who are married or in a civil partnership in the foreign-born population of the South West (49 per cent) is higher than that for the UK-born population (43 per cent). The percentage of the foreign-born population married or in a civil partnership is higher than the percentage of those who are single (37 per cent). This differs from the UK-born population where the population single (42 per cent) is similar to the married/civil partnered population.

The South West has one of the highest percentages of foreign-born people of White ethnic origin (71 per cent) in 2009. A further 11 per cent of the foreign-born population are of Asian ethnic origin. There are also notable percentages of people from 'other' (7 per cent) and Black (7 per cent) ethnic origins. The UK-born population have an even greater percentage of people of a White ethnic background, with 98 per cent of the population in this category.

For many of the religious groups represented in the South West, the confidence intervals for those born in the UK and those born elsewhere overlap. This means that assumptions about religious differences between them cannot be made with any certainty. However, it can be concluded from the available figures that foreign-born people are mostly Christians (72 per cent). This is similar to the percentage of the UK-born population who are Christian (76 per cent). The percentage of the foreign-born population of no religion (15 per cent) is lower than the UK-born population (23 per cent).

Of the employed, the percentage of the foreign-born population in elementary occupations (17 per cent) is higher than the UK-born population (11 per cent). Otherwise, the percentages of both the foreign- and UK-born in each occupation are similar.

In the South West, the foreign-born population earn similar median net weekly amounts to that of the UK-born population (£262 and £265 respectively). The foreign-born population from EU26 nations earn less than this (£250); however, those from the rest of the world earn more (£272).

In 2009, the foreign-born population of the South West is more likely to hold any type of qualification (89 per cent) than the UK-born population (85 per cent). The proportion of the foreignborn population with degrees ( 24 per cent) is similar to the UK-born population ( 25 per cent).

\section{Wales}

The foreign-born population make up 5 per cent of the total population of Wales (approximately 150,000 people) in 2009. This is one of the smallest percentages of foreign-born populations over all the regions and countries and makes up only 2 per cent of the total foreign-born population of the UK.

The largest percentage of the foreign-born population are in the 30 to 44-year-old age group (31 per cent), compared with 18 per cent of the UK-born population. Substantial differences are also 
evident between the foreign-born and UK-born populations in the 65-years-and-over age group. Here the foreign-born percentage is 10 per cent while the UK-born percentage is 18 per cent. Further, there is a large difference between the foreign-born and UK-born percentages within the 0 to 15-year-old age group. Here the UK-born percentage is more sizeable (19 per cent) than that for the foreign-born percentage (11 per cent).

More people in the foreign-born population of Wales are married or in a civil partnership (50 per cent) than the UK-born population (41 per cent) in 2009. Conversely, the percentage of singles in the foreign-born population is smaller (36 per cent) than that of the UK-born population (44 per cent).

In 2009 , the most common ethnic background for the foreign-born population is White (59 per cent). This is followed by people of an Asian ethnic origin (19 per cent) and those from 'other' ethnic origins (13 per cent). The UK-born population of Wales differs from this; 98 per cent of this population is of a White ethnic origin.

The most common religion found among the foreign-born population of Wales is the Christian religion (60 per cent). Those with no religion (16 per cent) and Muslims (15 per cent) also make up a sizeable percentage. This differs from the UK-born population where 70 per cent of the population are Christian and the only other notable category is those with no religion (28 per cent).

Of those employed in Wales, there is a higher percentage of those working in elementary occupations (19 per cent) than the UK-born population (12 per cent).

A higher proportion of the foreign-born and UK-born populations in Wales have qualifications; 82 per cent of the foreign-born population have qualifications compared with 77 per cent of the UKborn population. A larger percentage of the foreign-born population have a degree (30 per cent) than the UK-born population (22 per cent).

The foreign-born population of Wales earn a lower net weekly median wage (£245) than the UKborn population (£254). The foreign-born population from EU26 nations earn less than the UK-born population (£231), while those from the rest of the word earn the same (£254).

\section{Scotland}

The foreign-born population make up 6 per cent of the total population of Scotland (approximately 320,000 people) in 2009. This accounts for 5 per cent of the total foreign-born population of the UK.

The largest age group for the foreign-born population is the 30 to 44-year-old age group (32 per cent). This differs from the UK-born population where only 20 per cent are in this age group. Large differences are also seen for the 25 to 29-year-old age group, which comprise 18 per cent of the foreign-born population, but just 6 per cent of the UK-born population in 2009. The opposite is true for the 65 and over age group where the UK-born percentage is much larger at 17 per cent than the foreign-born population (7 per cent).

The percentage of people who are married or in a civil partnership in the foreign-born population of Scotland (45 per cent) is higher than the UK-born population (40 per cent) in 2009 , while there are 
similar percentages of foreign-born and UK-born single people (46 per cent and 45 per cent respectively).

Two-thirds of the foreign-born population in Scotland are of a White ethnic background (67 per cent), and 16 per cent are of an Asian ethnic background. This is very different to the UK-born population where 99 per cent of the population are of a White ethnic background.

More than half the foreign-born population in Scotland are Christian (59 per cent) though for the Christian UK-born population the percentage is larger (74 per cent). The next largest percentage for both populations is no religion; 19 per cent of the foreign-born population are in this group, and 24 per cent of the UK-born population. In 2009, there is also a notable percentage of Muslims in the foreign-born population (13 per cent), which is much higher than the UK-born Muslim population (1 per cent).

Of the employed, the occupations of the foreign-born population are similar to those of the UK-born population. However, there are higher percentages of the foreign-born than the UK-born population in professional occupations (17 per cent, compared with 13 per cent) and elementary occupations (17 per cent compared with 12 per cent), and there are smaller proportions of the foreign-born population in the associate professional and technical occupations ( 8 per cent) than the UK-born population (12 per cent).

Using a net weekly median wage, the foreign-born population earn less than the UK-born population ( $£ 260$ and $£ 277$ respectively). The foreign-born population from EU26 nations earn less (£231), however, those from the rest of the world earn more (£300).

The percentage of the foreign-born population with qualifications (84 per cent) is greater than the percentage of the UK-born population with qualifications (79 per cent). The same is seen in the percentages of both populations with degrees; a third (33 per cent) of the foreign-born population hold a degree in 2009 , compared with just over a quarter (26 per cent) of the UK-born population.

\section{Northern Ireland ${ }^{16}$}

The foreign-born population of Northern Ireland make up 6 per cent of the total population of the country (approximately 100,000 people) and 1 per cent of the total foreign-born population of the UK in 2009. This is the smallest proportion among all the English regions and UK countries.

The greatest difference between the foreign-born and UK-born populations in Northern Ireland in 2009 is for the 30 to 44 -year-old age group; 32 per cent of the foreign-born population are in this age group, compared with 20 per cent of the UK-born population. There is also a substantially higher percentage of foreign-born people in the 25 to 29-year-old age group; 14 per cent compared with only 7 per cent of the UK-born population. Conversely; the percentage of the foreign-born population in the 45 to 64 -year-old age group is notably smaller; 16 per cent compared with 24 per cent of the UK-born population.

The percentage of those who are married or in a civil partnership in the foreign-born population of Northern Ireland (45 per cent) is larger than the UK-born population (40 per cent). Similar

\footnotetext{
${ }^{16}$ Data on religion are not collected in Northern Ireland; therefore this profile does not include a paragraph on this subject.
} 
proportions of foreign- and UK-born populations are single (49 per cent and 45 per cent respectively).

The largest ethnic group of the foreign-born population in Northern Ireland is the White ethnic group (78 per cent). In comparison, near all of the UK-born population in Northern Ireland are in this group. It should be noted that the other ethnic groups for this region have unacceptable coefficients of variation, which means that the estimates and their observed differences cannot be considered reliable.

With regard to net weekly median earnings, the foreign-born population of Northern Ireland earn less (£212) than the UK-born population (£254). The foreign-born population from EU26 nations earn even less at $£ 200$, while those from the rest of the world earn approximately $£ 221$.

The percentage of the foreign-born population with qualifications (64 per cent) is similar to the UKborn population (66 per cent). The percentage of the foreign-born population with degrees (24 per cent) is similar to that for the UK-born population (22 per cent).

\section{Summary}

Analysis of APS data for 2009 show that foreign-born people are not spread evenly throughout the UK; rather, they are clustered within certain areas. By region and country, London has the largest foreign-born population, and also has the largest percentage of its total population who are foreignborn. The South of England, East of England and the West Midlands also have larger proportions of their total population who are foreign-born, while the North East and Northern Ireland have the smallest proportions.

One of the most notable differences between the foreign-born and UK-born populations is the age structures of the two populations. The age structure of the foreign-born population in 2009 varies across the UK regions and countries, while that of the UK-born population is relatively uniform. The 30 to 44-year-old age group make up the largest percentage of foreign-born people in each region. For the UK-born, the 45 to 64-year-old age group make up the largest percentage in each region. The exception to this is London where the 30 to 44 -year-old age group have a slightly higher percentage.

The percentages of married/civil partnered and single people also differ between the foreign-and UK-born populations. With the exception of London, the UK-born population has relatively similar percentages of married or civil partnered people and single people across the regions and countries in 2009. This is not the case for the foreign-born population. There are more married/civil partnered foreign-born people than single people in most parts of the UK, with the only exceptions being Scotland and Northern Ireland. In the UK-born population, more people are single than are in marriages or civil partnerships in all regions except the South West.

With one exception, in all regions and countries the largest ethnic group for the foreign-born population is White. The exception to this is the West Midlands where Asian is the largest ethnic group.

Within each region and country, the most common religion for both the foreign- and UK-born populations is Christianity. For the foreign-born population, the Muslim population is also sizeable 
in percentage terms in most regions and countries. Similar proportions of the foreign-born population of no religion are evident within most regions and countries, although the percentage of the UK-born population of no religion is higher.

The types of occupation in which the foreign-born population are employed varies by region and country and differs from the occupations of the UK-born population.

The percentage of the foreign-born population with health problems varies across the regions and countries of the UK; however, the percentage of the foreign-born population with health problems is typically lower than that for the UK-born population.

A smaller proportion of foreign-born people claim state benefits/tax credits than UK-born people for most regions and countries. The percentage of all people that claim state benefit/tax credits varies by region and country for both populations, though this is more evident within the foreign-born population. 


\section{Annex A}

\section{The Annual Population Survey background}

The Annual Population Survey (APS) is part of the larger Labour Force Survey (LFS) of households conducted in the UK by the Office for National Statistics and the Central Survey Unit of the Department of Finance and Personnel in Northern Ireland. The LFS is a quarterly sample survey of households living at private addresses in the UK. Its purpose is to provide information on the UK labour market that can then be used to develop, manage, evaluate and report on labour market policies.

The survey is divided into five 'waves' representing repeated interviews of the same respondents. The first wave represents respondents who are interviewed for the first time; the second wave represents people who are interviewed for the second time, and so on. Quarterly periods of the survey are organised such that each contains a mixture of people from all five possible waves. The first interview of a respondent is conducted face-to-face and subsequent interviews are conducted by telephone. An interviewee may supply responses for other members of their household and about a third of the survey responses are collected in this way (by proxy).

The survey data are processed on a quarterly basis and are released as both a quarterly and rolling-quarterly-annual dataset. The rolling-quarterly-annual dataset is referred to as the APS. The key differences between the quarterly LFS datasets and APS are: the APS is a combination of waves one and five only whereas the LFS quarterly data includes all waves; the APS includes an additional annual sample boost element. The use of waves one and five only in the APS ensures there is no replication of respondent's details within each annual dataset. The data used in this report refer to the APS dataset from January to December 2009.

The population included in the LFS refers to all people living in private households, students living away from home in halls of residence during term-time, and those in NHS accommodation (that is, nurses). The sample frame for the survey is the Royal Mail Postcode Address File (PAF) and the NHS special accommodation list. However, the sample for the area north of the Caledonian Canal in Scotland is drawn from the telephone directory because it is sparsely populated and would be costly to survey on a face-to-face basis (here all interviews are conducted by phone).

Detailed information on the background and methodology of the survey can be found in the LFS User Guide Volume 1 (www.statistics.gov.uk/statbase/Product.asp?vlnk=1537). 
Office for

National Statistics

8 June 2011

\section{Correction Notice Regional Trends}

\section{Portrait of the South East}

A production error affecting the Article 'Portrait of the South East', which was originally published 20 January 2011 , has been corrected,

Incorrect information about the sources of crime statistics was included in the article on page 30. The statistics were unaffected. The erroneous information has now been removed and pages 30 and 31 have been slightly rearranged.

ONS apologises for any inconvenience caused.

Issued by:

Office for National Statistics

Government Buildings

Cardiff Road

NewportNP10 8XG 